\title{
The effect of $A N K K 1$ Taq1A and DRD2 C957T polymorphisms on executive function: a systematic review and meta-analysis
}

\author{
Klaus, K. ${ }^{1}$, Butler, K. ${ }^{1}$, Curtis, F. ${ }^{2}$, Bridle, C. ${ }^{2}$, Pennington, K. ${ }^{1 *}$ \\ ${ }^{1}$ School of Psychology, University of Lincoln, Brayford Wharf, Lincoln, UK, LN5 7AT \\ ${ }^{2}$ Lincoln Institute for Health, University of Lincoln, Brayford Pool, Lincoln, UK, LN6 7TS
}

*Address of corresponding author:

Dr Kyla Pennington

Sarah Swift Building, School of Psychology, University of Lincoln, Brayford Wharf, Lincoln, UK, LN5 7AT

Email: kpennington@lincoln.ac.uk

Tel. +44(0)1522886199 


\begin{abstract}
Research in healthy adults suggests that C957T polymorphism of the dopamine D2 receptor encoding $D R D 2$ and the Taq1A polymorphism of the neighbouring gene ankyrin repeat and kinase domain containing $1(A N K K l)$ alter dopaminergic signalling and may influence prefrontally-mediated executive functions. A systematic review and meta-analysis was carried out on the evidence for the association of DRD2 C957T and ANKK1 Taq1A polymorphisms in performance on tasks relating to the three core domains of executive function: working memory, response inhibition and cognitive flexibility in healthy adults. CINAHL, MEDLINE, PsycARTICLES and PsychINFO databases were searched for predefined key search terms associated with the two polymorphisms and executive function. Studies were included if they investigated a healthy adult population with the mean age of 18-65 years, no psychiatric or neurological disorder and only the healthy adult arm were included in studies with any casecontrol design. Data from 17 independent studies were included in meta-analysis, separated by the Taq1A and C957T polymorphisms and by executive function tests: working memory (Taq1A, 6 samples, $n=1270$; C957T, 6 samples, $n=977$ ), cognitive flexibility (C957T, 3 samples, $n=620$ ), and response inhibition (C957T, 3 samples, $n=598)$. The meta-analyses did not establish significant associations between these gene polymorphisms of interest and any of the executive function domains. Theoretical implications and methodological considerations of these findings are discussed.
\end{abstract}

Keywords: ANKK1 Taq1A, DRD2 C957T, executive function, working memory, cognitive flexibility, response inhibition 


\section{Introduction}

Growing evidence suggests that many of the gene variants associated with mental health disorders such as schizophrenia, bipolar disorder and depression are also linked to underlying cognitive processes fundamental to enabling effective reasoning and problemsolving, decision-making, and future planning (Schwarz, Tost, \& Meyer-Lindenberg, 2016; Zai, Robbins, Sahakian, \& Kennedy, 2017). Working memory, response inhibition and cognitive flexibility are components of these processes and are often grouped under the umbrella term of executive function (Diamond, 2013). Executive function deficits often precede the onset of schizophrenia (Fusar-Poli et al., 2012), in addition to having a key role in mood (Rock, Roiser, Riedel, \& Blackwell, 2014) and addiction related disorders (Goldstein \& Volkow, 2002; Redish, Jensen, \& Johnson, 2008). Dysfunction in the prefrontal and the associated subcortical circuitries is thought to mediate these processes (Arnsten \& Rubia, 2012; Nowrangi, Lyketsos, Rao, \& Munro, 2014). Understanding the genetic basis of individual endophenotypes known to confer risk is key in enabling the polygenic basis of the disorder to be better understood in terms of its component parts (Gur et al., 2007; Schizophrenia Working Group of the Psychiatric Genomics, 2014).

One of the key neurotransmitter systems known to influence the activity and functioning of the prefrontal cortex (PFC) is dopamine and dopamine dysfunction is welldocumented in disorders in which executive function deficits play a key role. The dopamine hypothesis of schizophrenia was conceptualised in the 1970s, suggesting that dopamine dysfunction is central to the pathophysiology of psychosis and schizophrenia (Snyder, 1976). Indeed, it is well established that certain components of the dopaminergic system, such as presynaptic dopamine and dopamine synthesis, are increased in the striatum of individuals with at high risk of psychosis (Fusar-Poli et al., 2012) and striatal dopamine has been linked to altered cortical function during cognitive tasks in schizophrenia (Meyer-Lindenberg et al., 
2002). Striatal and frontal dopaminergic abnormalities are also investigated in attention deficit hyperactivity disorder (ADHD), as well as drug and alcohol abuse disorders that are characterised by deficits in inhibitory control (Volkow, Fowler, Wang, Swanson, \& Telang, 2007). Psychostimulants that increase dopaminergic activity produce symptoms akin to mania even in healthy participants (Cousins, Butts, \& Young, 2009) and dopaminergic gene variants have also been implicated in schizophrenia, bipolar disorder, mood disorders and substance abuse disorders (Cousins et al., 2009; Munafo, Matheson, \& Flint, 2007; Palomo, Kostrzewa, Beninger, \& Archer, 2007; Patriquin, Bauer, Soares, Graham, \& Nielsen, 2015; Savitz et al., 2013; Wu, Xiao, Sun, Zou, \& Zhu, 2012; Zai et al., 2017).

A recent systematic review and meta-analysis suggests a role for C957T single nucleotide polymorphism (SNP) of the dopamine D2 receptor encoding DRD2 (rs6277) and the Taq1A (rs1800497) SNP of the neighbouring gene ankyrin repeat and kinase domain containing 1 (ANKK1) in the development of schizophrenia (Gonzalez-Castro et al., 2016). These variants appear to have measurable effects on D2 receptor function and dopaminergic signalling. The DRD2 C957T has been proposed to influence D2 receptor availability via effects on receptor affinity with CC homozygosity being associated with lower striatal D2 receptor availability and putatively elevated striatal dopamine levels (Hirvonen et al., 2009a; Hirvonen et al., 2009b; Smith et al., 2017). CC homozygosity has also been associated with reduced performance in PFC-mediated executive functions such as working memory, response inhibition and cognitive flexibility (Klaus et al., 2017; Rodríguez-Jiménez et al., 2006; Xu et al., 2007). The risk allele of the Taq1A SNP (A1) has also been shown to affect D2 receptor availability (Pohjalainen et al., 1998), however, despite being in linkage disequilibrium with the C957T SNP it has been proposed that the Taq1A may influence density rather than affinity (Hirvonen et al, 2009) and some argue it may not have a significant effect on receptor availability at all (Smith et al., 2017). Despite this, carriers of the A1 allele have also been 
reported to have poorer performance in tasks related to executive function (Jocham et al., 2009; Stelzel, Basten, Montag, Reuter, \& Fiebach, 2010).

Although common gene variants such as SNPs are likely to only have a small effect on complex cognitive processes such as those involved in executive function (Barnes, Dean, Nandam, O'Connell, \& Bellgrove, 2011; Savitz, Solms, \& Ramesar, 2006), some gene variants may have a greater effect than others and consequently it is important to investigate whether the processes through which these key gene variants may confer vulnerability to mental health disorders converge on cognitive processes known to also be associated with risk. This systematic review aimed to collate the current evidence base for the effects of DRD2 rs6277 and the ANKK1 Taq1A rs1800497 genotype variation on cognitive performance in healthy adults as evaluated through the three core domains of executive function: working memory, response inhibition and cognitive flexibility (Diamond, 2013). Although all these processes are mediated by PFC, previous research has shown that specific aspects of executive function are associated with distinct patterns of brain activation (Jurado \& Rosselli, 2007; Logue \& Gould, 2014; Wager \& Smith, 2003). Separate meta-analyses will therefore be carried out for the different executive function domain tasks. It is hoped that this study will build on work aiming to delineate the cognitive neuroscience of mental health vulnerability in order to better understand the sub-clinical phenotypes which may be key to onset and treatment response.

\section{Methods}

Methods for carrying out the systematic review and meta-analysis were specified in advance and published in a protocol on PROSPERO on 13/01/17 (International Prospective Register of Systematic Reviews; www.crd.york.ac.uk/PROSPERO/) with identifier CRD42017042833. 


\subsection{Search strategy}

EBSCOhost search engine was accessed on $18^{\text {th }}$ June 2018 to search CINAHL, MEDLINE, PsycARTICLES, and PsycINFO databases. The search terms used were: DRD2 OR ANKK1 AND Taq-1a OR Taq-Ia OR Taq1A OR TaqIa OR C32806T OR Glu713Lys OR rs1800497 OR C957T OR rs6277 OR Pro319Pro AND "executive function*" OR inhibit* OR "working memory" OR updat* OR "cognitive flexibility" OR shift* OR switch*. The initial search terms were identified using previous reviews on the core executive function domains, i.e. working memory, cognitive flexibility and response inhibition (Diamond, 2013), and additional keywords relating to these executive function domains were found using the review article by Baggetta and Alexander (2016), which summarised the most commonly used terms and constructs that have been used in executive function research. Medical sub-headings (MeSH) were additionally scanned for relevant keywords. These resulting terms were searched within full text of the papers with no restrictions on publishing date. The searches were limited to human studies and the articles published in English language. Reference lists of relevant reviews and original research articles were hand searched to find articles missed by the original search, supplemented with additional Internet searches (Google Scholar). Study authors and research groups were contacted to retrieve data and information not included in the original papers.

\subsection{Inclusion/exclusion criteria}

Eligible studies satisfied the following criteria: 1) investigated a healthy adult population, i.e. no diagnosis of any psychiatric, neurological, or other medical condition, with the mean age of the participants between 18-65 years; 2) investigated either DRD2 C957T or ANKK1 Taq1A polymorphism; 3) investigated the executive function domains of working 
memory, cognitive flexibility or response inhibition using cognitive function tests. Only data from the healthy adult arm in the case-control studies were included.

\subsection{Study selection}

All titles and abstracts identified through the primary search and hand search were screened for relevance by two authors (KK and KP). Subsequently, full texts of potentially eligible studies were retrieved and screened to determine their eligibility for the review by the same two investigators. Discrepancies were resolved through discussion.

\subsection{Data extraction}

Data were extracted by one reviewer (KP or KK) and checked for accuracy by a second reviewer (KK or KP). A standardised, pre-piloted form was used for data extraction. The following information was extracted: 1) first author and year; 2) participant demographics, including the number of participants (males/females), age (mean and standard deviation [SD] of age, or age range where the mean age was not given), ethnicity, diagnostic status, and the inclusion/exclusion criteria used in the study; 3) the gene polymorphism studied, genotype distributions, and whether the genotype frequencies conformed to HardyWeinberg Equilibrium (HWE); 4) cognitive domain investigated, cognitive tests and outcome measures used; 5) statistical analysis methods used and whether codominance or recessive model was assumed; 6) number of dropouts and final number of participants used in the analyses, main results (means and SD where available); 7) authors'/reviewers' comments.

\subsection{Quality assessment}

The Effective Public Health Practice Project (EPHPP) Quality Assessment Tool (Thomas, Ciliska, Dobbins, \& Micucci, 2004) was used to assess the quality of each study. 
The following components were rated: Selection Bias, Study Design, Confounders (ethnicity, age, educational background and history of mental illness), Blinding, Data Collection Methods, and Withdrawals/Dropouts. These individual components were rated as strong, moderate or weak according to the scoring criteria, the 'Quality Assessment Tool for Quantitative Studies Dictionary'. The component ratings were further combined into a global quality rating (strong, moderate or weak) based on the tool's scoring criteria. Global ratings were strong if there were no weak component ratings, moderate where there was one weak component rating, and weak if the study had two or more weak component ratings.

Some modifications were made to the EPHPP to be more relevant for the studies assessed in this review. Although some studies implemented a randomised controlled trial or controlled clinical trial design, all studies were scored as cohort analytic in the Study Design section, as only data from healthy/placebo arm were extracted. Data Collection Methods section was rated with reference to cognitive tasks. If modifications of standard tasks were used, these were not rated as valid or reliable unless this was explicitly addressed in the paper or in a cited paper. Question 2 (Q2) of the Blinding component is intended to evaluate whether the participant is aware of the research question. In the context of the current review, this was interpreted as whether the participant was aware of their genotype. However, notifying the participant of their genotype before cognitive testing is not a common practice and none of the included studies explicitly reported this information. Therefore, Q2 was removed and the Blinding component was scored using Q1 only. Two additional aspects of quality were assessed, although these were not included in the global rating. Firstly, homogeneity of the population in terms of race/ethnicity was checked and secondly, whether the distribution of genetic polymorphisms conformed to HWE (seen in Table 1 and Table 2). Quality was assessed independently by $\mathrm{KK}$ and $\mathrm{KB}$, and disagreements were settled by KP. 


\subsection{Data analysis}

Data were grouped based on the two polymorphisms of interest and meta-analyses were carried out for each of these polymorphisms. Although the performance on working memory, response inhibition and cognitive flexibility tests are attributable to the function of the PFC, the specific cognitive processes may be associated with the activation in specific, separate cerebral areas (Jurado \& Rosselli, 2007; Logue \& Gould, 2014; Wager \& Smith, 2003). Separate meta-analyses were therefore carried out for these three executive function domains. For studies that reported several outcome measures or the results for several cognitive tests, the outcome that was conceptually and/or directionally most comparable to other studies was selected.

In accordance with the proposed inverted U-shaped dopamine function, whereby intermediate levels of dopamine are optimal for PFC functioning (Cools \& D'Esposito, 2011), all C957T genotypes were compared against each other. For Taq1A analyses, A1A1 and A1A2 genotypes were pooled together due to the rarity of A1A1 genotype, therefore resulting in A1+ and A1- groups. Where the data was presented for A1A1 and A1A2 genotypes separately (Gong et al., 2012; Markett, Montag, \& Reuter, 2010; Stelzel, Basten, Montag, Reuter, \& Fiebach, 2009), the combined means were calculated by weighing the means of both groups as follows:

$$
\bar{X}_{1}=\frac{n_{1} \bar{X}_{1}+n_{2} \bar{X}_{2}}{n_{1}+n_{2}}
$$

The combined standard deviations were computed as:

$$
S=\sqrt{\frac{\left(n_{1}-1\right) S_{1}^{2}+\left(n_{2}-1\right) S_{2}^{2}+\frac{n_{1} n_{2}}{n_{1}+n_{2}}\left(\bar{X}_{1}-\bar{X}_{2}\right)^{2}}{n_{1}+n_{2}-1}}
$$


where $\bar{X}_{1}$ and $\bar{X}_{2}$ are the subgroup means, $n_{1}$ and $n_{2}$ denote the subgroup sample sizes and $S_{1}$, $S_{2}$ the subgroup standard deviations. Where standard errors (SE) were given, these were converted to standard deviations as follows:

$\mathrm{S}=\mathrm{SE} \sqrt{(n)}$

Where a higher score indicated poorer performance (e.g. the number of errors in Klaus et al., 2017), the variable was reversed using the following formula:

New Value $=$ Maximum Value + Minimum Value - Old Value

All analyses were conducted using Review Manager version 5.3 (The Cochrane Collaboration, 2014). Standardised mean difference estimates between the different genotypes were calculated using Cohen's d and confidence intervals (CI) were also computed. Due to expected heterogeneity between study population characteristics, randomeffects model was chosen. Heterogeneity between studies was assessed using Higgins $\mathrm{I}^{2}$ statistic (Higgins and Thompson, 2002). A $p$ value of 0.05 was considered significant. In an attempt to reduce expected heterogeneity in the working memory tasks, the studies were further divided into phonological and visual/visuospatial working memory tasks for unplanned subgroup analyses broadly based on Baddeley and Hitch (1994) categories. The working memory tasks were categorised as phonological if the task required storing subvocally rehearsable material such as letters or digits, and tasks were included in the visual/visuospatial category if storage of visual features (e.g. colour) or spatial information was needed (Moran, 2016).

Sensitivity analyses were undertaken by omitting single studies from each metaanalysis in order to assess the effect of these studies on the pooled effect size in the overall model and in the subgroup analyses. A study was omitted if it differed from the other studies 
based on the pre-specified potentially confounding variables (age, education, ethnicity, history of mental illness), as these factors may impact on cognitive outcomes (Brockmole \& Logie, 2013; Byrd, Touradji, Tang, \& Manly, 2004; Huguelet, Zanello, \& Nicastro, 2000; Wight et al., 2006), and it has further been shown that the effects of age, education, ethnicity and mental illness on cognitive outcomes may depend on DRD2 genotype (Colzato, van den Wildenberg, \& Hommel, 2013; Nkam et al., 2017; Villalba, Devieux, Rosenberg, \& Cadet, 2015; Wight et al., 2006). We further explored the effect of other factors, including the cognitive tasks and study quality on meta-analysis outcomes.

\section{Results}

\subsection{Search results}

The initial database, reference list and the Internet search identified 145 studies after

the removal of duplicates (Figure 1). Eighty-nine studies were excluded at this stage based on the title and abstract scanning, leaving 56 papers to be retrieved and checked against the inclusion criteria. Of these, four papers contained study populations whose mean age was not within the 18-65 range or the participants could not be characterised as healthy, two studies did not investigate Taq1A or C957T polymorphism. Further, 17 studies used cognitive tests other than those measuring working memory, response inhibition or cognitive flexibility, or the outcome measures were not comparable to the measures used in other studies. Authors were contacted to request outcome measures in 20 cases due to insufficient data in the published paper (means and SD not supplied). Data could not be obtained for 14 papers either because the authors did not reply, executive function was not investigated as an outcome measure, or polygenic score rather than individual polymorphisms were investigated. Seventeen studies were included in the meta-analysis. However, it should be noted some 
studies investigated more than one executive function domain and some investigated both polymorphisms in the same study. This resulted in 12 reports of the association between the two polymorphisms of interest and working memory (six reports of Taq1A and six reports of C957T), three reports of response inhibition (all reports of C957T), and seven reports of cognitive flexibility (four and three reports of Taq1A and C957T, respectively; see Figure 1, Table 1 and Table 2).

\section{*FIGURE 1*}


Table 1. Characteristics of the Studies Investigating the ANKK1 Taq1A Polymorphism

\begin{tabular}{|c|c|c|c|c|c|c|c|}
\hline Study & Cognitive domain & $\mathbf{F} / \mathbf{M}(n)$ & $\begin{array}{c}\text { Age } \\
M(S D) \\
\end{array}$ & Ethnicity & HWE & Test & Outcome measure \\
\hline Ariza et al. (2012) & $\begin{array}{l}\text { WM-phonological } \\
\text { CF }\end{array}$ & $\begin{array}{l}\text { F } 29 \\
\text { M } 13\end{array}$ & $29.67(6.97)$ & $\begin{array}{c}3 \text { Hispanics } \\
39 \text { Caucasians }\end{array}$ & Not reported & $\begin{array}{l}\text { WM: WAIS-III Letter- Number } \\
\text { Sequencing } \\
\text { CF: WCST }\end{array}$ & $\begin{array}{l}\text { WM: No. of correct } \\
\text { sequences } \\
\text { CF: Number of } \\
\text { perseverative errors }\end{array}$ \\
\hline $\begin{array}{l}\text { Berryhill, Wiener, } \\
\text { Stephens, Lohoff, } \\
\text { and Coslett (2013) }\end{array}$ & WM-visual & $\begin{array}{l}\text { F } 81 \\
\text { M } 53\end{array}$ & $22.8(6.00)$ & Majority Caucasian \pm & Not reported & $\begin{array}{l}\text { Sequential presentation object } \\
\text { WM paradigm }\end{array}$ & $\begin{array}{l}\text { Corrected recognition (set } \\
\text { size } 6 \text {, delay } 5 \mathrm{~s} \text { ) }\end{array}$ \\
\hline Butcher (2014) & WM-visuospatial & $\begin{array}{l}\text { F } 11 \\
\text { M } 11\end{array}$ & $25.1(5.63)$ & $\begin{array}{c}17 \text { Caucasians, } 2 \text { Asians, } \\
\text { 3 Latinos }\end{array}$ & Not reported & Spatial WM task & $\begin{array}{l}\text { Average accuracy (high } \\
\text { load) }\end{array}$ \\
\hline Gong et al. (2012) & WM-phonological & $\begin{array}{l}\text { F } 400 \\
\text { M } 282\end{array}$ & Range $19-21^{*}$ & Chinese Han & Yes & Digital WM arithmetic based task & $\begin{array}{l}\text { The number of addends } \\
\text { and subtrahends } \\
\text { remembered }\end{array}$ \\
\hline Jocham et al. (2009) & $\mathrm{CF}$ & $35 \mathrm{M}^{* *}$ & $\begin{array}{l}\mathrm{A} 1+=25.92 \\
\mathrm{~A} 1-=26.33\end{array}$ & Caucasian & $* * *$ & $\begin{array}{l}\text { Probablistic reversal learning } \\
\text { task }\end{array}$ & Reversal errors \\
\hline $\begin{array}{l}\text { Markett et al. } \\
(2010)\end{array}$ & WM-visuospatial & $\begin{array}{l}\text { F } 83 \\
\text { M } 18\end{array}$ & $24.74(6.45)$ & White & Yes & Brief visual array task & Cowan’s K (K6) \\
\hline Nkam et al. (2017) & $\mathrm{CF}$ & $\begin{array}{l}34 \mathrm{~F} \\
19 \mathrm{M}\end{array}$ & $43.77(12.18)$ & Not reported & Not reported & WCST & $\begin{array}{c}\text { Number of perseverative } \\
\text { errors }\end{array}$ \\
\hline Stelzel et al. (2009) & WM-phonological & $\begin{array}{l}\text { F } 154 \\
\text { M } 142\end{array}$ & $\begin{array}{l}\text { M } 23.0(2.64) \\
\text { F } 22.64(2.56)\end{array}$ & Caucasian (German) & Yes & $\begin{array}{l}\text { WAIS-III Digit Span Backward } \\
\text { and Letter-Number Sequencing }\end{array}$ & $\begin{array}{l}\text { Mean factor values } \\
\text { (combined across tasks) }\end{array}$ \\
\hline Stelzel et al. (2010) & $\mathrm{CF}$ & $\begin{array}{l}24 \mathrm{~F} \\
24 \mathrm{M}\end{array}$ & $\begin{array}{l}\text { F } 22.0(1.99) \\
\text { M } 22.6(1.99)\end{array}$ & $\begin{array}{l}\text { Caucasian } \\
\text { (German) }\end{array}$ & $* * * *$ & Task-switching paradigm & Task-switching costs (RT) \\
\hline
\end{tabular}

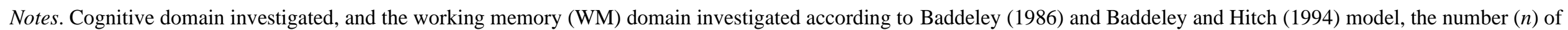
females $(\mathrm{F})$ and males $(\mathrm{M})$ in each study group, means $(M)$ and standard deviations $(S D)$ of age, ethnicity, whether the genotype frequencies conformed to Hardy-Weinberg

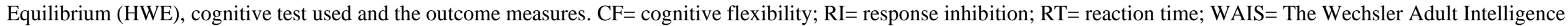

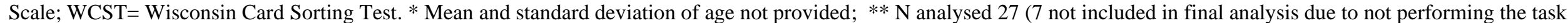
satisfactorily or having an excess of switching behaviour or due a malfunction in the presentation system); *** Larger sample was in HWE. Sample used in current study was

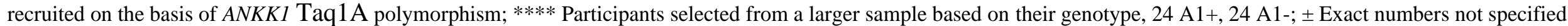


Table 2. Characteristics of the Studies Investigating the DRD2 C957T Polymorphism

\begin{tabular}{|c|c|c|c|c|c|c|c|}
\hline Study & Cognitive domain & F/M $(n)$ & $\begin{array}{c}\text { Age } \\
M(S D)\end{array}$ & Ethnicity & HWE & Test & Outcome measure \\
\hline Bellander et al. (2015) & WM-visuospatial & $\begin{array}{l}\text { F } 52 \\
\text { M } 49\end{array}$ & $25.6(2.7)$ & Not specified & Yes & Spatial n-back & $\begin{array}{l}\text { Baseline data, latent } \\
\text { means and SD }\end{array}$ \\
\hline $\begin{array}{l}\text { Beste, Stock, Epplen, } \\
\text { and Arning (2016) }\end{array}$ & RI & $\begin{array}{l}108 \mathrm{~F} \\
87 \mathrm{M}\end{array}$ & $23.9(3.1)$ & Caucasian descent & Yes & Go/No-Go & False alarms \\
\hline Colzato et al. (2016) & $\begin{array}{c}\text { WM-phonological } \\
\text { RI }\end{array}$ & $\begin{array}{l}\text { F } 67 \\
\text { M } 14\end{array}$ & $\begin{array}{l}\text { CC } 20.5 \\
\text { CT } 19.8 \\
\text { TT } 19.9\end{array}$ & 100\% Caucasian (Dutch) & Yes & $\begin{array}{l}\text { WM: Letter-based version of } \\
\text { the n-back; computerised } \\
\text { RI: Stop signal task }\end{array}$ & $\begin{array}{l}\text { WM: No. of hits (3-back) } \\
\text { RI: Stop signal reaction } \\
\text { time }\end{array}$ \\
\hline $\begin{array}{l}\text { Gurvich and Rossell } \\
\text { (2014) }\end{array}$ & RI & $\begin{array}{l}\text { F } 169 \\
\text { M } 153\end{array}$ & $41.1(16.74)$ & European & Yes & Go/No-Go & False positives \\
\hline $\begin{array}{l}\text { Gurvich and Rossell } \\
\text { (2015) }\end{array}$ & $\begin{array}{c}\text { WM-phonological } \\
\text { CF }\end{array}$ & $\begin{array}{l}\text { F } 206 \\
\text { M } 209\end{array}$ & $37.46(18.76)$ & $100 \%$ European & Yes & $\begin{array}{c}\text { WM: Digit Span Backwards; } \\
\text { computerised } \\
\text { CF: Trails B }\end{array}$ & $\begin{array}{l}\text { WM: Max. no. of digits } \\
\text { recalled without an error } \\
\text { CF: No. of times incorrect } \\
\text { digit letter was pressed }\end{array}$ \\
\hline Klaus et al. (2017) & $\begin{array}{l}\text { WM-visuospatial } \\
\text { CF }\end{array}$ & M 122 & $35.15(11.02)$ & $\begin{array}{c}115 \text { Caucasians, } \\
2 \text { mixed race origin, } 2 \\
\text { Asian/Asian British, } 2 \\
\text { Iranian/British Iranian, } 1 \text { Arab }\end{array}$ & Yes & $\begin{array}{c}\text { WM: Spatial WM task } \\
\text { CF: Intra-extradimensional set } \\
\text { shift }\end{array}$ & $\begin{array}{l}\text { WM: No. of errors }{ }^{ \pm} \\
\text {CF: No. of errors }\end{array}$ \\
\hline Markett et al. (2010) & WM-visuospatial & $\begin{array}{l}\text { F } 83 \\
\text { M } 18\end{array}$ & $24.74(6.45)$ & $100 \%$ White & Yes & Brief visual array task & Cowan's K (K6) \\
\hline $\begin{array}{l}\text { Markett, Montag, } \\
\text { Walter, and Reuter } \\
\text { (2011) }\end{array}$ & WM-phonological & $\begin{array}{l}\text { F } 112 \\
\text { M } 25\end{array}$ & $23.9(5.7)$ & $100 \%$ Caucasian & Yes & Digit Span Backward (WAIS) & $\begin{array}{c}\text { The sum of correct } \\
\text { answers }\end{array}$ \\
\hline $\begin{array}{l}\text { Rodriguez-Jimenez et } \\
\text { al. (2006) }\end{array}$ & $\mathrm{CF}$ & $\begin{array}{l}55 \mathrm{~F} \\
28 \mathrm{M}\end{array}$ & $25.2(1.7)$ & Caucasian & Yes & WCST & Perseverative errors \\
\hline
\end{tabular}

Notes. See Table 1 legend.

${ }^{ \pm}$variable reverse-coded for analysis; $\$$ Same study investigated both Taq1A and C957T polymorphisms 


\subsection{Findings for the $A N K K 1$ Taq1A polymorphism}

Six studies (Ariza et al., 2012; Berryhill et al., 2013; Butcher, 2014; Gong et al., 2012; Markett et al., 2010; Stelzel et al., 2009) focused on Taq1A polymorphism in the context of working memory performance (total of 1270 participants). Within the six studies, the A1+ group consisted of a total of 670 individuals, while the A1-group consisted of 600 participants. The samples in all but one study (Butcher et al. 2016) used predominantly female participants, while Butcher et al. tested an equal number of males and females. The mean age of the participants ranged from 22.64 to 29.67 years, with only Gong et al. (2012) testing younger participants in the age range of 19-21 years. Gong et al. (2012) investigated a Chinese population, while the rest of the study populations could be classified as “majority/all Caucasian/White". Three studies (Ariza et al., 2012; Berryhill et al., 2013; Butcher, 2014) did not report HWE, and another three found no deviations from HWE. The six investigated studies used different working memory tasks, or combined the results from several tasks (e.g., Stelzel et al., 2009). However, further division into phonological and visual/visuospatial working memory domains resulted in three studies investigating phonological working memory domain and three investigating visual/visuospatial working memory (see Table 1).

The overall random-effects between-group meta-analysis did not detect an association between working memory performance and Taq1 A genotype, $d=-.07,95 \%$ CI $[-.38, .25]$, $p=.67$, and there was considerable heterogeneity between studies, $I^{2}=80 \%$ (see Figure 2). Division of working memory tasks into phonological and visual/visuospatial working memory domains did not lead to any significant associations between Taq1A polymorphism and working memory performance $(d=-.22,95 \% \mathrm{CI}-.73, .29, p=.39$ and $d=.13,95 \% \mathrm{CI}-.12$, $.39, p=.30$, for phonological and visual/visuospatial working memory task subgroups, respectively). The study heterogeneity for Taq1A analyses remained considerable for 
phonological working memory subgroup, $I^{2}=90 \%$, but was eliminated for visual/visuospatial working memory subgroup, $I^{2}=0 \%$ (Figure 2).

\section{*FIGURE 2*}

Four studies investigated Taq1A polymorphism in the context of cognitive flexibility (Ariza et al., 2012; Jocham et al., 2009; Nkam et al., 2017; Stelzel et al., 2010). These studies resulted in a total of 163 participants, with 50 participants in the A1+ group and 113 participants in the A1- group (Figure 3). Ariza et al. (2012) and Nkam et al. (2017) study samples consisted of predominantly female participants, Stelzel et al. (2010) investigated an equal number of males and females, and Jocham et al. (2009) investigated males only. Nkam et al. (2017) did not report the participant ethnicity, whereas the rest of the studies reported testing primarily or all Caucasian participants. The participants in all studies except Nkam and colleagues' study investigated participants with the mean age in their 20 s, whereas the mean participant age in Nkam and colleague's study was over 40 years. The studies either did not report HWE (Ariza et al., 2012; Nkam et al., 2017) or the participants were selected for inclusion in the study from a larger study based on their genotype for the purpose of equal group sizes (Jocham et al., 2009; Stelzel et al., 2010). Two studies (Ariza et al., 2012; Nkam et al., 2017) investigated cognitive flexibility using the WCST, and another two studies used variations of cognitive flexibility tasks (Table 1). Analyses on Taq1A polymorphism and its association with cognitive flexibility revealed no significant results, $d=-.47$, CI [-1.20, 0.25], $p=.20$, and the results showed substantial heterogeneity, $I^{2}=70 \%$ (Figure 3 ). 


\section{*FIGURE 3*}

\subsection{Findings for the DRD2 C957T polymorphism}

Six studies (Bellander et al., 2015; Colzato et al., 2016; Gurvich \& Rossell, 2015;

Klaus et al., 2017; Markett et al., 2011; Markett et al., 2010) focused on DRD2 C957T

polymorphism in the context of working memory performance (total of 977 participants), and the number of participants in CC, CT and TT groups were 224, 435, and 318, respectively (Figures 4a-4c). One study investigated a male-only population (Klaus et al., 2017), two studies had approximately equal number of males and females (Bellander et al., 2015; Gurvich \& Rossell, 2015) and the remaining studies investigated samples consisting mostly of female participants (Colzato et al., 2016; Markett et al., 2011; Markett et al., 2010). The mean age of the participants ranged from 19.8 to 37.46 years. The ethnicity could be described as predominantly White/Caucasian in five studies, while one study (Bellander et al., 2015) did not specify the ethnicity of the participants. All studies except one (Bellander et al., 2015) reported that the genotype distributions conformed to HWE, whereas Bellander and colleagues did not provide information on this. Two studies used Digit Span Backwards task (Gurvich \& Rossell, 2015; Markett et al., 2011) and the remaining studies used different working memory tasks. Three studies implemented phonological working memory tasks and three used visuospatial working memory tasks (see Table 2).

The overall random effects model found no association between C957T genotype and working memory performance, $p>.05$ in all cases, and the heterogeneity between studies varied depending on the genotypes compared, with CT and TT comparisons showing no inconsistency, $I^{2}=0 \%, \mathrm{CC}$ and TT subgroup comparisons showing low inconsistency across studies, $I^{2}=27 \%$, and CC and CT comparisons showing substantial inconsistency, $I^{2}=68 \%$ 
(see Figures 4a-4c). Subgroup analyses failed to find a significant association between C957T polymorphism and working memory performance, $p>.05$ in all cases, although a marginally significant difference was seen between the performance of CC and TT homozygotes on phonological working memory tasks, $d=.20,95 \%$ CI [-.01, .41], $p=.07$, with CC carriers showing superior performance. Heterogeneity was eliminated from phonological working memory subgroup, $I^{2}=0 \%$. Studies investigating the C957T polymorphism and visual/visuospatial working memory component maintained heterogeneity, with some inconsistency found in all comparisons (CC vs TT, $I^{2}=39 \%$; CT vs TT, $I^{2}=45 \%$; CC vs CT, $I^{2}=82 \%$; Figures $\left.4 \mathrm{a}-4 \mathrm{c}\right)$.

\section{*FIGURES 4A, 4B, 4C*}

Three studies (Gurvich \& Rossell, 2015; Klaus et al., 2017; Rodriguez-Jimenez et al., 2006) investigated C957T polymorphism in the context of cognitive flexibility (total of 620 participants), with 132 participants in CC genotype group, 293 in CT group and 195 in TT group (Figures 5a-5c). As noted previously, Klaus et al. (2017) tested a sample of male participants, whereas Gurvich and Rossell (2015) and Rodriguez-Jimenez et al. (2006) used a mixed sample of males and females. The mean participant age ranged from 25.2 to 37.46 between these studies. All studies used predominantly Caucasian (or European) participants, and the genotype distributions conformed to HWE. Klaus et al. (2017) and RodriguezJimenez et al. (2006) both used variations of WCST, whereas Gurvich and Rossell (2015) used a Trails B task (Table 2). The analyses on the association between DRD2 C957T polymorphism and cognitive flexibility did not reveal any significant associations, $p>.05$ in all cases. There was considerable study heterogeneity for CC and TT comparisons $\left(I^{2}=75 \%\right)$ 
and for CC and CT comparisons $\left(I^{2}=85 \%\right)$. No heterogeneity was detected for CT and TT comparisons $\left(I^{2}=0 \%\right.$; see Figures $\left.5 \mathrm{a}-5 \mathrm{c}\right)$.

*FIGURES 5A, 5B, 5C*

Three studies (Beste et al., 2016; Colzato et al., 2016; Gurvich \& Rossell, 2014) investigated the association between $D R D 2$ C957T polymorphism and response inhibition (total of 598 participants), with 149 participants in the CC group, 292 in the CT group and 157 in TT group (Figures 6a-6c). All studies used mixed gender samples, with the mean age ranging from 19.8 to 41.1 years. The participants in all studies were primarily of Caucasian (or European) descent, and genotype distributions in all studies conformed to HWE. One study used stop signal (Colzato et al., 2016) and two used Go/No-Go tasks (Beste et al., 2016; Gurvich \& Rossell, 2014), see Table 2. The analyses on the association between DRD2 C957T polymorphism and response inhibition similarly failed to find significant associations, p>.05 in all cases. Study heterogeneity was considerable for CC and TT comparisons $\left(I^{2}=97 \%\right)$ and for CC and CT comparisons $\left(I^{2}=98 \%\right)$ and substantial for CT and TT comparisons $\left(I^{2}=70 \%\right.$; see Figures $\left.6 \mathrm{a}-6 \mathrm{c}\right)$.

*FIGURES 6A, 6B, 6C*

\subsection{Study quality}

Component and global ratings for the quality assessment can be seen in Table 3. Twelve studies were given a weak global rating and five were assessed as having moderate quality, with none of the studies achieving a strong global rating. The weak global ratings were mostly 
driven by the Selection Bias, Confounders, and Data Collection Method components. All but two studies (Gong et al., 2012; Nkam et al., 2017) were rated as weak on Selection Bias, as the participants were not likely to be representative of the general population or less than $60 \%$ of the approached or screened individuals agreed to participate in the study. Alternatively, the study received a weak rating if the participant selection process and the level of participation were not described. Twelve studies were given weak ratings on Confounders component, because it was not possible to tell whether there were important differences between the groups in terms one or more of the relevant confounders (age, education level, ethnicity, history of mental illness), and it was not clear how many of the relevant confounders were controlled for, or less than $60 \%$ of the confounders were controlled for. Nine studies were given weak ratings on Data Collection Methods, because the reliability and validity of the data collection tools were not described.

However, 13 studies achieved a strong rating on Withdrawals/Dropouts section, as the percentage of participants completing the study was at or above $80 \%$. All studies used design that could have been described as cohort analytic design and were therefore given moderate rating on Study Design subsection. Although there were some randomised controlled trials, controlled clinical trials and case-control studies (Ariza et al., 2012; Colzato et al., 2016; Nkam et al., 2017), these were rated as cohort analytic because data was only extracted from the placebo arm. All studies were rated as moderate or strong on the Blinding component, as the researcher was either not aware of the genotype of the participant (strong) or it was not possible to tell whether the researcher knew the participant's genotype (moderate). Eleven studies reported that the genotype frequencies conformed to HWE, whereas four studies did not provide information on this, and for two studies the participants were chosen into the study based on their Taq1A genotype (Table 1 and Table 2). 
Table 3. Results From the Quality Assessment for the Studies Included in the Meta-Analysis

\begin{tabular}{|c|c|c|c|c|c|c|c|}
\hline Author & $\begin{array}{l}\text { Selection } \\
\text { bias }\end{array}$ & Study Design & Confounders & Blinding & $\begin{array}{l}\text { Data Collection } \\
\text { Methods }\end{array}$ & $\begin{array}{l}\text { Withdrawals/ } \\
\text { Dropouts }\end{array}$ & $\begin{array}{l}\text { Global } \\
\text { Rating }\end{array}$ \\
\hline Ariza et al. (2012) & Weak & Moderate & Moderate & Moderate & Strong & Moderate & Moderate \\
\hline Bellander et al. (2015) & Weak & Moderate & Weak & Strong & Weak & Weak & Weak \\
\hline Berryhill et al. (2013) & Weak & Moderate & Weak & Moderate & Weak & Strong & Weak \\
\hline Beste et al. (2016) & Weak & Moderate & Weak & Moderate & Weak & Strong & Weak \\
\hline Butcher (2014) & Weak & Moderate & Weak & Moderate & Weak & Moderate & Weak \\
\hline Colzato et al. (2016) & Weak & Moderate & Strong & Strong & Weak & Strong & Weak \\
\hline Gong et al. (2012) & Moderate & Moderate & Strong & Moderate & Weak & Strong & Moderate \\
\hline $\begin{array}{l}\text { Gurvich and Rossell } \\
\text { (2014) }\end{array}$ & Weak & Moderate & Weak & Moderate & Strong & Strong & Weak \\
\hline $\begin{array}{l}\text { Gurvich and Rossell } \\
\text { (2015) }\end{array}$ & Weak & Moderate & Weak & Moderate & Strong & Strong & Weak \\
\hline Jocham et al. (2009) & Weak & Moderate & Weak & Moderate & Weak & Strong & Weak \\
\hline Klaus et al. (2017) & Weak & Moderate & Moderate & Strong & Strong & Strong & Moderate \\
\hline
\end{tabular}


Table 3. Results From the Quality Assessment for the Studies Included in the Meta-Analysis (continued)

\begin{tabular}{|c|c|c|c|c|c|c|c|}
\hline Author & $\begin{array}{l}\text { Selection } \\
\text { bias }\end{array}$ & Study Design & Confounders & Blinding & $\begin{array}{l}\text { Data Collection } \\
\text { Methods }\end{array}$ & $\begin{array}{l}\text { Withdrawals/ } \\
\text { Dropouts }\end{array}$ & $\begin{array}{l}\text { Global } \\
\text { Rating }\end{array}$ \\
\hline Markett et al. (2010) & Weak & Moderate & Weak & Moderate & Weak & Strong & Weak \\
\hline Markett et al. (2011) & Weak & Moderate & Weak & Moderate & Strong & Strong & Weak \\
\hline Nkam et al. (2017) & Moderate & Moderate & Weak & Moderate & Strong & Strong & Moderate \\
\hline $\begin{array}{l}\text { Rodriguez-Jimenez et al. } \\
\text { (2006) }\end{array}$ & Weak & Moderate & Moderate & Moderate & Strong & Strong & Moderate \\
\hline Stelzel et al. (2009) & Weak & Moderate & Weak & Strong & Strong & Strong & Weak \\
\hline Stelzel et al. (2010) & Weak & Moderate & Weak & Moderate & Weak & Weak & Weak \\
\hline
\end{tabular}

Note. Quality assessment was carried out using The Effective Public Health Practice Project (EPHPP) Quality Assessment Tool 


\subsection{Sensitivity analyses}

Of the studies included in these meta-analyses, only one reported using nonCaucasian participants (Gong et al., 2012). As ethnicity was regarded as one of the potential confounding variables, the analyses on the Taq1A and working memory association were repeated after excluding the study by Gong and colleagues. The results from the overall model remained non-significant, $d=-.10,95 \% \mathrm{CI}[-.52, .32], p=.65$, and the heterogeneity between studies remained considerable, $I^{2}=79 \%$. Results from the phonological working memory subgroup analyses showed a marginally significant effect of the Taq1A genotype on working memory performance, $d=-.44,95 \% \mathrm{CI}[-.90, .02], p=.06$, with better performance in the A1- group. The heterogeneity in the subgroup analyses was considered moderate, $I^{2}=.50$. Seventeen studies did not control for or did not report controlling for at least one confounding variable (age, ethnicity, education, history of mental illness), and 14 studies did not control for or failed to report controlling for at least two confounding variables. Due to a high number of such studies, further sensitivity analyses on these variables were not feasible. We further investigated whether the results were dependent on the cognitive tests used. As seen in Tables 1 and 2, a number of different cognitive function tasks were used, and omitting single studies from the analyses based on cognitive tests would not have been informative, nor backed by theoretical reasoning. We therefore took an alternative approach and explored the changes in effect size and heterogeneity estimates by investigating only studies that used variations of the same cognitive task. In the context of Taq1A and cognitive flexibility, both Ariza and colleagues (2012) and Nkam and colleagues (2017) used WCST. When including only these studies in the meta-analysis, the results remained non-significant, $d=-.22,95 \% \mathrm{CI}$ $[-.80, .36], p=.52$, but heterogeneity was eliminated, $I^{2}=0$. In the context of $D R D 2$ C957T and working memory, two studies used Digit Span Backwards task (Gurvich \& Rossell, 2015; Markett et al., 2011). A meta-analysis of these two studies again did not produce significant 
findings, $p>.05$ in all cases, but heterogeneity was eliminated from all phonological working memory analyses, $I^{2}=0$. Both Klaus and colleagues (2017) and Rodriguez-Jimenez and colleagues (2006) implemented variations of the WCST. Analyses of these studies revealed a significant effect in DRD2 C957T CC and TT group analyses, $d=.46,95 \%$ CI $[.05, .87]$, $p=.03$, and CC and CT group analyses, $d=.67,95 \%$ CI $[.29,1.05], p<.001$, with CC group showing worse performance than CT or TT groups. CT and TT comparisons did not reveal a significant effect of genotype on cognitive flexibility, $d=-.19,95 \%$ CI $[-.50, .13], p=.24$. Statistical heterogeneity was eliminated from all analyses, $I^{2}=0$. For C957T and response inhibition, analyses on the two studies that used Go/No-Go tasks (Beste et al., 2016; Gurvich $\&$ Rossell, 2014) produced non-significant results, $p>.05$ for all cases and heterogeneity remained notable, ranging from 66 to $99 \%$ for the different genotype group analyses. Instead, heterogeneity was eliminated from CC and CT, as well as CC and TT analyses, $I^{2}=0$, and reduced for CT and TT analyses, $I^{2}=56 \%$, by removing Beste et al. (2016) study. However, the results after removal of Beste and colleagues' study remained non-significant, $p>.05$, and the reasons for this study driving the statistical heterogeneity could not be determined. Removal of studies based on poor study quality was not possible, as a high number of studies (12 altogether) were scored as having Weak global rating.

\section{Discussion}

\subsection{The association between dopaminergic gene variants and executive function}

The aim of this study was to systematically review and quantify the effects of two functional polymorphisms previously associated with mental health disorders such as schizophrenia, ANKK1 Taq1A and DRD2 C957T (Gonzalez-Castro et al., 2016), on the performance in executive function tests in healthy adults. More specifically, this review focused on the performance on working memory, cognitive flexibility and response inhibition 
tasks. The findings from these meta-analyses suggest that Taq1A and C957T have a limited if any effect on executive function in healthy adults, but the overall models also showed evidence of high study heterogeneity. In an attempt to reduce heterogeneity, working memory tasks were further subdivided into phonological and visual/visuospatial working memory tasks. The resulting subgroup analyses eliminated heterogeneity from Taq1A visual/visuospatial working memory task analyses, and C957T phonological working memory subgroup analyses, and showed a marginally significant difference between C957T $\mathrm{CC}$ and TT homozygotes on phonological working memory tasks. Study heterogeneity remained high for most other analyses, which might have contributed to the lack of significant findings. Further sensitivity analyses were carried out to investigate the sources of statistical heterogeneity, such as variation in cognitive tests used, and the results may suggest some evidence of C957T on cognitive flexibility, whereby CC group shows worse performance compared to other groups. This is the first study to systematically review these polymorphisms in the context of executive function but the results are in accord with some of the other meta-analyses which have found limited effect of SNPs on cognitive performance (Barnett, Scoriels, \& Munafò, 2008; Mandelman \& Grigorenko, 2012; Rincon-Perez, Sanchez-Carmona, Albert, \& Hinojosa, 2018).

There are several possible explanations for the current findings. Firstly, it might be argued that these polymorphisms indeed have a limited effect on executive function. This potential explanation is supported by the subgroup analyses, whereby the non-significance of the results remained largely unchanged even after heterogeneity was reduced by creating phonological and visual/visuospatial working memory subgroups. Although a marginally significant difference in the DRD2 C957T CC and TT homozygotes' performance on phonological working memory tasks was seen, this association was not strong enough to draw clear conclusions. The limited effect of single SNPs on endophenotypic outcomes is 
perhaps not surprising, as genome-wide association studies have demonstrated the complex polygenic nature of cognitive abilities (Trampush et al., 2017), as well as the mental health disorders characterised by executive function deficits such as schizophrenia (Schizophrenia Working Group of the Psychiatric Genomics Consortium, 2014), addiction (Treutlein \& Rietschel, 2011) and ADHD (Hinney et al., 2011). Secondly, it could be argued that these polymorphisms impact on intermediate phenotypes at a neural level that do not translate directly to effects on executive function. In support of this idea, a recent meta-analysis found that Taq1A minor allele (A1) is associated with decreased striatal D2 binding potential (Gluskin \& Mickey, 2017) and C957T has similarly been associated with D2 binding potential in both striatal (Hirvonen et al., 2004, 2005) and extrastriatal regions (Hirvonen et al., 2009b). Alternatively, it might be argued that these polymorphisms have an effect on cognitive endophenotypes not investigated in the current meta-analysis, such as reward responsivity (Davis et al., 2008). Lastly, as any effects of single SNPs on cognitive function are expected to be small (Trampush et al., 2017), it is possible that small but true effects of these gene variants on executive function exist, but were supressed due to limitations such as heterogeneity between studies entered in the meta-analyses.

\subsection{Heterogeneity between studies}

The results from the meta-analyses showed substantial or considerable heterogeneity in many of the analyses, which may have partly stemmed from the differences between cognitive tests used, study populations investigated and the lack of control over confounding variables. An overview of the methodologies used for investigating executive function revealed that the studies have been inconsistent in the use of executive function tests which might have diminished any detectable effect of these polymorphisms on executive function performance. Furthermore, results from the quality assessment showed that nine studies did 
not state whether the cognitive tests used were reliable and valid, or the reliability and the validity of the tools was not known, which may have introduced further variability in the cognitive test outcomes. Owing to the different executive function tasks used, the studies also reported a variety of outcome measures. To overcome this limitation, we chose the outcome measures that were most comparable to those reported across studies and picked the most taxing version if different difficulty levels were investigated). Nevertheless, harmonisation of the outcome measures was not possible for the two studies that investigated ANKK1 Taq1A polymorphism in the context of response inhibition using variations of stop signal task (Weafer et al., 2017; White et al., 2008). Whereas Weafer and colleagues (2017) used the number of inhibitory failures as an outcome measure, White and colleagues (2008) focused on the percentage of inhibited responses. As no data transformation was possible in order to make the outcome measures comparable, no meta-analysis was carried out on these studies. Another study (White et al., 2009) had to be omitted from the C957T and response inhibition analyses due to the directionality issue. Regarding working memory tasks, whereas some studies used simple count-based outcome measures such as the number of correct answers (e.g. Ariza et al., 2012; Gong et al., 2012), others provided complex measures taking into account factors such as hits, correct rejections and sample size (e.g. Cowan's K; Markett et al., 2010), which led to inconsistency in the reported outputs. The notion of different tests leading to statistical heterogeneity was supported by sensitivity analyses, which showed that when only the studies that used (variations of) the same cognitive tests were included in the analyses, statistical heterogeneity was eliminated from many of the analyses.

Another source of heterogeneity might have been the variability in study populations investigated. The majority of the studies used mixed gender samples or were dominated by female participants, with only Klaus et al. (2017) and Jocham et al. (2009) using a male-only sample. The genotype-by-gender interaction on cognitive outcomes has been noted for 
C957T (Gurvich \& Rossell, 2015) and a recent meta-analysis by Gluskin and Mickey (2017) suggested that gender might mediate the effect of Taq1A on D2 binding potential, with a weaker effect of Taq1A genotype noted in males. Although the neurobiological basis of these sex differences have not been fully delineated, sex steroids are likely to play a role, as both oestrogen and testosterone have shown to affect D2 receptor expression in rodent models (Al Sweidi, Morissette, Rouillard, \& Di Paolo, 2013; Purves-Tyson et al., 2014; Sarvari et al., 2014). Unfortunately, stratification by sex was not possible in the current analyses. Secondly, the sensitivity analyses on the Taq1A carrier working memory performance showed that the removal of the Gong and colleagues' (2012) Chinese sample resulted in A1- carriers showing better performance on phonological working memory tasks at a marginal significance level, therefore perhaps suggesting ethnicity-specific effects of Taq1A genotype on working memory performance. However, clear conclusions cannot be drawn, as these results were only based on two samples and were largely driven by Stelzel and colleagues' (2009) findings. Furthermore, quality assessment showed that 12 studies failed to control (or did not report controlling) for several of the potential confounders, including age, education level, ethnicity, and history of mental illness, all of which may affect outcomes on the cognitive tests either directly or via interaction with genotype (Brockmole \& Logie, 2013; Byrd et al., 2004; Colzato et al., 2013; Huguelet et al., 2000; Nkam et al., 2017; Villalba et al., 2015; Wight et al., 2006).

\subsection{Studies not included in the meta-analyses}

The current meta-analyses might also have been biased because some studies that reported significant association between the Taq1A or C957T genotype and the performance on executive function tasks could not be included in the analyses. For example, the study by $\mathrm{Xu}$ and colleagues (2007) who investigated the effect of C957T polymorphism on working 
memory outcomes was excluded from the meta-analysis due to insufficient data being available, but the authors report significantly poorer performance of $\mathrm{CC}$ homozygotes compared to CT and TT carriers in a Word Serial Position Test (WSPT), a verbal working memory test. The authors claim this finding suggests deficits in maintaining phonological and serial order information in the $\mathrm{CC}$ homozygotes and may partly explain the verbal memory deficits seen in some schizophrenia patients tested on WSPT. However, the authors reported no significant differences between the genotypes in other working memory tests including an n-back test, the WAIS-III Letter-Number Sequencing, and the Spatial Delayed-Response test. Another study (Jacobsen, Pugh, Mencl, \& Gelernter, 2006) similarly reported worse working memory performance in C957T CC homozygotes, who showed impaired performance compared to the $\mathrm{T}$ allele carriers in an $\mathrm{n}$-back test. However, Jacobsen and colleagues' study combined both smokers and non-smokers in their analyses with the smokers meeting the Diagnostic and Statistical Manual of Mental Disorders (DSM-4; American Psychiatric Association, 1994) criteria for nicotine dependence. With the data for the healthy arm not separable, these data could not be included in the meta-analysis. A third study not included in the meta-analysis, conducted by Sundararajan (2012) found better performance in Taq1A A1+ group in a spatial working memory task, but only when age was included as a betweensubjects variable. Two other studies mentioned above, which could not be integrated into the meta-analyses due to incomparability of the outcome measures (Weafer et al., 2017; White et al., 2008) showed better performance in A1+ carriers compared to A- carriers. On the other hand, some studies have noted that C957 CC homozygotes or C carriers were more successful in inhibiting responses on a stop signal task (Colzato et al., 2013; Colzato, van den Wildenberg, Van der Does, \& Hommel, 2010). There have also been reports of negative findings in relation to C957T and executive function (White et al., 2009; Mitaki et al., 2013). Lastly, it should be noted that the sample sizes in several studies included in the meta- 
analysis were relatively small, which might have resulted in limited statistical power in the overall results.

\subsection{Strengths and future directions}

However, there were also some strengths to the meta-analytic results reported here. All studies included in this review used participants with the mean age under 45 years, suggesting that age was not likely to bias the results. Further, the dropout/withdrawal rate was generally low across studies and in majority of the cases the experimenters were likely to have been blind to the genotype of the participants, therefore not biasing the results. Although a number of different executive function tests was used, particularly for working memory analyses, all studies except Berryhill et al. (2013) and Butcher (2014) included working memory manipulation, rather than simple working memory maintenance tasks, with the former but not the latter requiring the involvement of central executive according to Baddeley and Hitch (1994) model. Therefore, the tasks used were rather homogenous in terms of the working memory domain (maintenance vs manipulation) investigated and involved the activation of similar underlying brain regions, such as the dIPFC and ventromedial PFC (Jolles, Kleibeuker, Rombouts, \& Crone, 2011; Veltman, Rombouts, \& Dolan, 2003). However, as dissociable patterns of brain activation has been noted between working memory maintenance and manipulation, as well as spatial and non-spatial tasks (Wager \& Smith, 2003), future studies could investigate the effect of Taq1 A and C957T polymorphisms on other working memory components. Furthermore, although stop signal task and Go/NoGo tasks both provide information on response inhibition, stop-signal task additionally shows the time taken to inhibit the response (as measured by SSRT) therefore providing information on "action restraint" and "action cancellation", respectively (Rincon-Perez et al., 2018). Although it was not possible to distinguish between these aspects of response inhibition in the 
current meta-analysis, this may be of interest in future studies. It might also be that these polymorphisms affect other cognitive processes such as reward sensitivity, which may be investigated in future studies (Davis et al., 2008). Finally, as C957T and Taq1A are in moderate linkage disequilibrium with each other and in strong linkage disequilibrium with other variants (Zhang et al., 2007), future studies could consider more complex interactions between different polymorphisms, as well as composite risk scores on executive function.

\subsection{Conclusions}

In sum, the current meta-analysis suggests that ANKK1 Taq1A and DRD2 C957T polymorphisms have limited if any effect on the performance on executive function tasks in healthy adults. However, the findings also show great heterogeneity in the assessment methods, outcome measures and study populations used, which may have concealed any detectable effect of genotype on executive function. Given the functional significance of both Taq1A and C957T in affecting striatal and cortical D2 receptor availability (Gluskin \& Mickey, 2017; Hirvonen et al., 2004, 2005; Hirvonen et al., 2009b), the possibility for a role of these polymorphisms in some aspects of executive function or other cognitive processes should not be excluded. 


\section{Role of funding source}

This work was supported by the University of Lincoln College of Social Science PhD studentship to KK.

\section{Conflict of interest}

All authors report no potential conflicts of interest. 


\section{References}

1. Al Sweidi, S., Morissette, M., Rouillard, C., \& Di Paolo, T. (2013). Estrogen receptors and lesion-induced response of striatal dopamine receptors. Neuroscience, 236, 99-109. doi:10.1016/j.neuroscience.2012.12.058

2. American Psychiatric Association. (1994). DSM-IV: Diagnostic and statistical manual. Washington (DC): American Psychiatric Association.

3. Ariza, M., Garolera, M., Jurado, M. A., Garcia-Garcia, I., Hernan, I., Sanchez-Garre, C., . . . Narberhaus, A. (2012). Dopamine genes (DRD2/ANKK1-TaqA1 and DRD4-7R) and executive function: their interaction with obesity. PloS One, 7(7), e41482. doi:10.1371/journal.pone.0041482

4. Arnsten, A. F. T., \& Rubia, K. (2012). Neurobiological Circuits Regulating Attention, Cognitive Control, Motivation, and Emotion: Disruptions in Neurodevelopmental Psychiatric Disorders. Journal of the American Academy of Child and Adolescent Psychiatry, 51(4), 356367. doi:10.1016/j.jaac.2012.01.008

5. Baddeley, A. (1986). Working memory. New York, NY: Clarendon Press.

6. Baddeley, A. D., \& Hitch, G. J. (1994). Developments in the concept of working memory. Neuropsychology, 8(4), 485.

7. Baggetta, P., \& Alexander, P. A. (2016). Conceptualization and operationalization of executive function. Mind, Brain, and Education, 10(1), 10-33. doi:10.1111/mbe.12100

8. Barnes, J. J., Dean, A. J., Nandam, L. S., O'Connell, R. G., \& Bellgrove, M. A. (2011). The molecular genetics of executive function: role of monoamine system genes. Biological Psychiatry, 69(12), e127-143. doi:10.1016/j.biopsych.2010.12.040

9. Barnett, J. H., Scoriels, L., \& Munafò, M. R. (2008). Meta-analysis of the cognitive effects of the catechol-O-methyltransferase gene Val158/108Met polymorphism. Biological Psychiatry, 64(2), 137-144. doi:10.1016/j.biopsych.2008.01.005 
10. Bellander, M., Backman, L., Liu, T., Schjeide, B. M., Bertram, L., Schmiedek, F., . . Lovden, M. (2015). Lower baseline performance but greater plasticity of working memory for carriers of the val allele of the COMT Val158Met polymorphism. Neuropsychology, 29(2), 247-254. doi:10.1037/neu0000088

11. Berryhill, M. E., Wiener, M., Stephens, J. A., Lohoff, F. W., \& Coslett, H. B. (2013). COMT and ANKK1-Taq-Ia genetic polymorphisms influence visual working memory. PloS One, 8(1), e55862. doi:10.1371/journal.pone.0055862

12. Beste, C., Stock, A. K., Epplen, J. T., \& Arning, L. (2016). Dissociable electrophysiological subprocesses during response inhibition are differentially modulated by dopamine D1 and D2 receptors. European Neuropsychopharmacology, 26(6), 1029-1036. doi:10.1016/j.euroneuro.2016.03.002

13. Brockmole, J. R., \& Logie, R. H. (2013). Age-related change in visual working memory: a study of 55,753 participants aged 8-75. Frontiers in Psychology, 4, 12. doi:10.3389/fpsyg.2013.00012

14. Butcher, P. A. (2014). Cortical-subcortical interactions in cognitive control, associative learning and motor control. University of California, Berkeley, California.

15. Byrd, D. A., Touradji, P., Tang, M. X., \& Manly, J. J. (2004). Cancellation test performance in African American, Hispanic, and White elderly. Journal of the International Neuropsychological Society, 10(3), 401-411. doi:10.1017/S1355617704103081

16. Colzato, L. S., Steenbergen, L., Sellaro, R., Stock, A. K., Arning, L., \& Beste, C. (2016). Effects of 1-Tyrosine on working memory and inhibitory control are determined by DRD2 genotypes: A randomized controlled trial. Cortex, 82, 217-224. doi:10.1016/j.cortex.2016.06.010 
17. Colzato, L. S., van den Wildenberg, W. P., \& Hommel, B. (2013). The genetic impact (C957T-DRD2) on inhibitory control is magnified by aging. Neuropsychologia, 51(7), 13771381. doi:10.1016/j.neuropsychologia.2013.01.014

18. Colzato, L. S., van den Wildenberg, W. P., Van der Does, A. J., \& Hommel, B. (2010). Genetic markers of striatal dopamine predict individual differences in dysfunctional, but not functional impulsivity. Neuroscience, 170(3), 782-788. doi:10.1016/j.neuroscience.2010.07.050

19. Cools, R., \& D'Esposito, M. (2011). Inverted-U-shaped dopamine actions on human working memory and cognitive control. Biological Psychiatry, 69(12), e113-125. doi:10.1016/j.biopsych.2011.03.028

20. Cousins, D. A., Butts, K., \& Young, A. H. (2009). The role of dopamine in bipolar disorder. Bipolar Disorders, 11(8), 787-806. doi:10.1111/j.1399-5618.2009.00760.x

21. Davis, C., Levitan, R. D., Kaplan, A. S., Carter, J., Reid, C., Curtis, C., . . Kennedy, J. L. (2008). Reward sensitivity and the D2 dopamine receptor gene: A case-control study of binge eating disorder. Progress in Neuro-Psychopharmacology and Biological Psychiatry, 32(3), 620-628. doi:10.1016/j.pnpbp.2007.09.024

22. Diamond, A. (2013). Executive functions. Annual Review in Psychology, 64, 135-168. doi:10.1146/annurev-psych-113011-143750

23. Fusar-Poli, P., Deste, G., Smieskova, R., Barlati, S., Yung, A. R., Howes, O., . . Borgwardt, S. (2012). Cognitive functioning in prodromal psychosis: a meta-analysis. Archives of General Psychiatry, 69(6), 562-571. doi:10.1001/archgenpsychiatry.2011.1592

24. Gluskin, B., \& Mickey, B. (2017). Genetic variation and dopamine D2 receptor availability: a systematic review and meta-analysis of human in vivo molecular imaging studies. Translational Psychiatry, 6(3), e747. doi:10.1038/tp.2016.22 
25. Goldstein, R. Z., \& Volkow, N. D. (2002). Drug addiction and its underlying neurobiological basis: neuroimaging evidence for the involvement of the frontal cortex. American Journal of Psychiatry, 159(10), 1642-1652. doi:10.1176/appi.ajp.159.10.1642

26. Gong, P., Zhang, H., Chi, W., Ge, W., Zhang, K., Zheng, A., . . Zhang, F. (2012). An association study on the polymorphisms of dopaminergic genes with working memory in a healthy Chinese Han population. Cellular and Molecular Neurobiology, 32(6), 1011-1019. doi:10.1007/s10571-012-9817-3

27. Gonzalez-Castro, T. B., Hernandez-Diaz, Y., Juarez-Rojop, I. E., Lopez-Narvaez, M. L., Tovilla-Zarate, C. A., Genis-Mendoza, A., \& Alpuin-Reyes, M. (2016). The role of C957T, TaqI and Ser311Cys polymorphisms of the DRD2 gene in schizophrenia: systematic review and meta-analysis. Behavoral and Brain Functions, 12(1), 29. doi:10.1186/s12993-016-0114$\mathrm{Z}$

28. Gur, R. E., Calkins, M. E., Gur, R. C., Horan, W. P., Nuechterlein, K. H., Seidman, L. J., \& Stone, W. S. (2007). The Consortium on the Genetics of Schizophrenia: neurocognitive endophenotypes. Schizophrenia Bulletin, 33(1), 49-68. doi:10.1093/schbul/sbl055

29. Gurvich, C., \& Rossell, S. L. (2015). Dopamine and cognitive control: sex-by-genotype interactions influence the capacity to switch attention. Behavioural Brain Research, 281, 96101. doi:10.1016/j.bbr.2014.11.045

30. Gurvich, C. T., \& Rossell, S. L. (2014). Genetic variations in dopamine and inhibitory control: lack of influence on action restraint. Behavioural Brain Research, 267, 12-16. doi:10.1016/j.bbr.2014.03.015

31. Hinney, A., Scherag, A., Jarick, I., Albayrak, Ö., Pütter, C., Pechlivanis, S., . . Scherag, S. (2011). Genome-wide association study in German patients with attention deficit/hyperactivity disorder. American Journal of Medical Genetics Part B: Neuropsychiatric Genetics, 156(8), 888-897. doi:10.1002/ajmg.b.31246 
32. Hirvonen, M., Laakso, A., Nagren, K., Rinne, J. O., Pohjalainen, T., \& Hietala, J. (2004). C957T polymorphism of the dopamine D2 receptor (DRD2) gene affects striatal DRD2 availability in vivo. Molecular Psychiatry, 9(12), 1060-1061. doi:10.1038/sj.mp.4001561

33. Hirvonen, M., Laakso, A., Nagren, K., Rinne, J. O., Pohjalainen, T., \& Hietala, J. (2005). C957T polymorphism of the dopamine D2 receptor (DRD2) gene affects striatal DRD2 availability in vivo. Molecular Psychiatry, 10(9), 889-889. doi:10.1038/sj.mp.4001707

34. Hirvonen, M. M., Laakso, A., Nagren, K., Rinne, J. O., Pohjalainen, T., \& Hietala, J. (2009a). C957T polymorphism of dopamine D2 receptor gene affects striatal DRD2 in vivo availability by changing the receptor affinity. Synapse, 63(10), 907-912. doi:10.1002/syn.20672

35. Hirvonen, M. M., Lumme, V., Hirvonen, J., Pesonen, U., Nagren, K., Vahlberg, T., . . . Hietala, J. (2009b). C957T polymorphism of the human dopamine D2 receptor gene predicts extrastriatal dopamine receptor availability in vivo. Progress in Neuro-Psychopharmacology and Biological Psychiatry, 33(4), 630-636. doi:10.1016/j.pnpbp.2009.02.021

36. Huguelet, P., Zanello, A., \& Nicastro, R. (2000). A study of visual and auditory verbal working memory in schizophrenic patients compared to healthy subjects. European Archives of Psychiatry and Clinical Neuroscience, 250(2), 79-85. doi:10.1007/s004060070039

37. Jacobsen, L. K., Pugh, K. R., Mencl, W. E., \& Gelernter, J. (2006). C957T polymorphism of the dopamine D2 receptor gene modulates the effect of nicotine on working memory performance and cortical processing efficiency. Psychopharmacology, 188(4), 530-540. doi:10.1007/s00213-006-0469-1

38. Jocham, G., Klein, T. A., Neumann, J., von Cramon, D. Y., Reuter, M., \& Ullsperger, M. (2009). Dopamine DRD2 polymorphism alters reversal learning and associated neural activity. Journal of Neuroscience, 29(12), 3695-3704. doi:10.1523/JNEUROSCI.519508.2009 
39. Jolles, D. D., Kleibeuker, S. W., Rombouts, S. A., \& Crone, E. A. (2011). Developmental differences in prefrontal activation during working memory maintenance and manipulation for different memory loads. Developmental Science, 14(4), 713-724. doi:10.1111/j.14677687.2010.01016.x

40. Jurado, M. B., \& Rosselli, M. (2007). The elusive nature of executive functions: a review of our current understanding. Neuropsychology Review, 17(3), 213-233.

41. Klaus, K., Butler, K., Durrant, S. J., Ali, M., Inglehearn, C. F., Hodgson, T. L., . . . Pennington, K. (2017). The effect of COMT Val158Met and DRD2 C957T polymorphisms on executive function and the impact of early life stress. Brain and Behavior, 7(5), e00695. doi:10.1002/brb3.695

42. Logue, S. F., \& Gould, T. J. (2014). The neural and genetic basis of executive function: attention, cognitive flexibility, and response inhibition. Pharmacology Biochemistry and Behavior, 123, 45-54. doi:10.1016/j.pbb.2013.08.007

43. Mandelman, S. D., \& Grigorenko, E. L. (2012). BDNF Val66Met and cognition: all, none, or some? A meta-analysis of the genetic association. Genes Brain and Behavior, 11(2), 127-136. doi:10.1111/j.1601-183X.2011.00738.X

44. Markett, S., Montag, C., Walter, N. T., \& Reuter, M. (2011). Evidence for the modality independence of the genetic epistasis between the dopaminergic and cholinergic system on working memory capacity. European Neuropsychopharmacology, 21(2), 216-220. doi:10.1016/j.euroneuro.2010.10.011

45. Markett, S. A., Montag, C., \& Reuter, M. (2010). The association between dopamine DRD2 polymorphisms and working memory capacity is modulated by a functional polymorphism on the nicotinic receptor gene CHRNA4. Journal Of Cognitive Neuroscience, 22(9), 19441954. doi:10.1162/jocn.2009.21354 
46. Meyer-Lindenberg, A., Miletich, R. S., Kohn, P. D., Esposito, G., Carson, R. E., Quarantelli, M., . . . Berman, K. F. (2002). Reduced prefrontal activity predicts exaggerated striatal dopaminergic function in schizophrenia. Nature Neuroscience, 5(3), 267-271. doi: $10.1038 / \mathrm{nn} 804$

47. Mitaki, S., Isomura, M., Maniwa, K., Yamasaki, M., Nagai, A., Nabika, T., \& Yamaguchi, S. (2013). Impact of five SNP s in dopamine-related genes on executive function. Acta Neurologica Scandinavica, 127(1), 70-76. doi:10.1111/j.1600-0404.2012.01673.x

48. Moran, T. P. (2016). Anxiety and working memory capacity: A meta-analysis and narrative review. Psychological Bulletin, 142(8), 831-864. doi:10.1037/bul0000051

49. Munafo, M., Matheson, I., \& Flint, J. (2007). Association of the DRD2 gene Taq1A polymorphism and alcoholism: a meta-analysis of case-control studies and evidence of publication bias. Molecular Psychiatry, 12(5), 454-461. doi:10.1038/sj.mp.4001938

50. Nkam, I., Ramoz, N., Breton, F., Mallet, J., Gorwood, P., \& Dubertret, C. (2017). Impact of DRD2/ANKK1 and COMT polymorphisms on attention and cognitive functions in schizophrenia. PloS One, 12(1), e0170147. doi:10.1371/journal.pone.0170147

51. Nowrangi, M. A., Lyketsos, C., Rao, V., \& Munro, C. A. (2014). Systematic review of neuroimaging correlates of executive functioning: converging evidence from different clinical populations. The Journal of Neuropsychiatry and Clinical Neurosciences, 26(2), 114125.

52. Palomo, T., Kostrzewa, R. M., Beninger, R. J., \& Archer, T. (2007). Genetic variation and shared biological susceptibility underlying comorbidity in neuropsychiatry. Neurotoxicity Research, 12(1), 29-42. doi:10.1007/BF03033899

53. Patriquin, M. A., Bauer, I. E., Soares, J. C., Graham, D. P., \& Nielsen, D. A. (2015). Addiction pharmacogenetics: a systematic review of the genetic variation of the 
dopaminergic system. Psychiatric Genetics, 25(5), 181-193.

doi:10.1097/YPG.0000000000000095

54. Pohjalainen, T., Rinne, J. O., Nagren, K., Lehikoinen, P., Anttila, K., Syvalahti, E. K., \& Hietala, J. (1998). The A1 allele of the human D2 dopamine receptor gene predicts low D2 receptor availability in healthy volunteers. Molecular Psychiatry, 3(3), 256-260.

55. Purves-Tyson, T. D., Owens, S. J., Double, K. L., Desai, R., Handelsman, D. J., \& Weickert, C. S. (2014). Testosterone induces molecular changes in dopamine signaling pathway molecules in the adolescent male rat nigrostriatal pathway. PloS One, 9(3), e91151. doi:10.1371/journal.pone.0091151

56. Redish, A. D., Jensen, S., \& Johnson, A. (2008). A unified framework for addiction: vulnerabilities in the decision process. Behavioral and Brain Sciences, 31(4), 415-437; discussion 437-487. doi:10.1017/S0140525X0800472X

57. Rincon-Perez, I., Sanchez-Carmona, A. J., Albert, J., \& Hinojosa, J. A. (2018). The association of monoamine-related gene polymorphisms with behavioural correlates of response inhibition: A meta-analytic review. Neuroscience and Biobehavioral Reviews, 84(Supplement C), 49-62. doi:10.1016/j.neubiorev.2017.11.009

58. Rock, P. L., Roiser, J. P., Riedel, W. J., \& Blackwell, A. D. (2014). Cognitive impairment in depression: a systematic review and meta-analysis. Psychological Medicine, 44(10), 20292040. doi:10.1017/S0033291713002535

59. Rodríguez-Jiménez, R., Avila, C., Ponce, G., Ibáñez, M. I., Rubio, G., Jiménez-Arriero, M. A., ... Palomo, T. (2006). The TaqIA polymorphism linked to the DRD2 gene is related to lower attention and less inhibitory control in alcoholic patients. European Psychiatry: The Journal Of The Association Of European Psychiatrists, 21(1), 66-69.

60. Rodriguez-Jimenez, R., Hoenicka, J., Jimenez-Arriero, M. A., Ponce, G., Bagney, A., Aragues, M., \& Palomo, T. (2006). Performance in the Wisconsin Card Sorting Test and the 
C957T polymorphism of the DRD2 gene in healthy volunteers. Neuropsychobiology, 54(3), 166-170. doi:10.1159/000098652

61. Sarvari, M., Deli, L., Kocsis, P., Mark, L., Maasz, G., Hrabovszky, E., . . L Liposits, Z. (2014). Estradiol and isotype-selective estrogen receptor agonists modulate the mesocortical dopaminergic system in gonadectomized female rats. Brain Research, 1583, 1-11. doi:10.1016/j.brainres.2014.06.020

62. Savitz, J., Hodgkinson, C. A., Martin-Soelch, C., Shen, P.-H., Szczepanik, J., Nugent, A. C., . . Drevets, W. C. (2013). DRD2/ANKK1 Taq1A polymorphism (rs1800497) has opposing effects on D2/3 receptor binding in healthy controls and patients with major depressive disorder. International Journal of Neuropsychopharmacology, 16(9), 2095-2101. doi:10.1017/S146114571300045X

63. Savitz, J., Solms, M., \& Ramesar, R. (2006). The molecular genetics of cognition: dopamine, COMT and BDNF. Genes, Brain and Behavior, 5(4), 311-328. doi:10.1111/j.1601183X.2005.00163.x

64. Schizophrenia Working Group of the Psychiatric Genomics, C. (2014). Biological insights from 108 schizophrenia-associated genetic loci. Nature, 511(7510), 421-427. doi:10.1038/nature13595

65. Schizophrenia Working Group of the Psychiatric Genomics Consortium. (2014). Biological insights from 108 schizophrenia-associated genetic loci. Nature, 511(7510), 421-427. doi:10.1038/nature13595

66. Schwarz, E., Tost, H., \& Meyer-Lindenberg, A. (2016). Working memory genetics in schizophrenia and related disorders: an RDoC perspective. American Journal of Medical Genetics Part B: Neuropsychiatric Genetics, 171(1), 121-131.

67. Smith, C. T., Dang, L. C., Buckholtz, J. W., Tetreault, A. M., Cowan, R. L., Kessler, R. M., \& Zald, D. H. (2017). The impact of common dopamine D2 receptor gene polymorphisms on 
D2/3 receptor availability: C957T as a key determinant in putamen and ventral striatum. Translational Psychiatry, 7(4), e1091. doi:10.1038/tp.2017.45

68. Snyder, S. H. (1976). The dopamine hypothesis of schizophrenia: focus on the dopamine receptor. American Journal of Psychiatry, 133(2), 197-202. doi:10.1176/ajp.133.2.197

69. Stelzel, C., Basten, U., Montag, C., Reuter, M., \& Fiebach, C. J. (2009). Effects of dopaminerelated gene-gene interactions on working memory component processes. European Journal of Neuroscience, 29(5), 1056-1063. doi:10.1111/j.1460-9568.2009.06647.x

70. Stelzel, C., Basten, U., Montag, C., Reuter, M., \& Fiebach, C. J. (2010). Frontostriatal involvement in task switching depends on genetic differences in $\mathrm{d} 2$ receptor density. Journal of Neuroscience, 30(42), 14205-14212. doi:10.1523/JNEUROSCI.1062-10.2010

71. Sundararajan, R. (2012). Effect of DBH, DRD2 and ADRA2A gene variants on human working memory. George Mason University.

72. Thomas, B., Ciliska, D., Dobbins, M., \& Micucci, S. (2004). A process for systematically reviewing the literature: providing the research evidence for public health nursing interventions. Worldviews on Evidence-Based Nursing, 1(3), 176-184. doi:10.1111/j.1524475X.2004.04006.X

73. Trampush, J., Yang, M., Yu, J., Knowles, E., Davies, G., Liewald, D., . . Sundet, K. (2017). GWAS meta-analysis reveals novel loci and genetic correlates for general cognitive function: a report from the COGENT consortium. Molecular Psychiatry, 22(3), 336. doi:10.1038/mp.2016.244

74. Treutlein, J., \& Rietschel, M. (2011). Genome-wide association studies of alcohol dependence and substance use disorders. Current Psychiatry Reports, 13(2), 147-155.

75. Veltman, D. J., Rombouts, S. A., \& Dolan, R. J. (2003). Maintenance versus manipulation in verbal working memory revisited: an fMRI study. Neuroimage, 18(2), 247-256. doi:10.1016/S1053-8119(02)00049-6 
76. Villalba, K., Devieux, J. G., Rosenberg, R., \& Cadet, J. L. (2015). DRD2 and DRD4 genes related to cognitive deficits in HIV-infected adults who abuse alcohol. Behavioral and Brain Functions, 11(1), 25. doi:10.1186/s12993-015-0072-х

77. Volkow, N. D., Fowler, J. S., Wang, G. J., Swanson, J. M., \& Telang, F. (2007). Dopamine in drug abuse and addiction: results of imaging studies and treatment implications. Archives of Neurology, 64(11), 1575-1579. doi:10.1001/archneur.64.11.1575

78. Wager, T. D., \& Smith, E. E. (2003). Neuroimaging studies of working memory. Cognitive, Affective, \& Behavioral Neuroscience, 3(4), 255-274.

79. Weafer, J., Gray, J. C., Hernandez, K., Palmer, A. A., MacKillop, J., \& de Wit, H. (2017). Hierarchical investigation of genetic influences on response inhibition in healthy young adults. Experimental and Clinical Psychopharmacology, 25(6), 512-520. doi:10.1037/pha0000156

80. White, M. J., Lawford, B. R., Morris, C. P., \& Young, R. M. (2009). Interaction between DRD2 C957T polymorphism and an acute psychosocial stressor on reward-related behavioral impulsivity. Behavior Genetics, 39(3), 285-295. doi:10.1007/s10519-008-9255-7

81. White, M. J., Morris, C. P., Lawford, B. R., \& Young, R. M. (2008). Behavioral phenotypes of impulsivity related to the ANKK1 gene are independent of an acute stressor. Behavioral and Brain Functions, 4, 54. doi:10.1186/1744-9081-4-54

82. Wight, R. G., Aneshensel, C. S., Miller-Martinez, D., Botticello, A. L., Cummings, J. R., Karlamangla, A. S., \& Seeman, T. E. (2006). Urban neighborhood context, educational attainment, and cognitive function among older adults. American Journal of Epidemiology, 163(12), 1071-1078. doi:10.1093/aje/kwj177

83. Wu, J., Xiao, H., Sun, H., Zou, L., \& Zhu, L. Q. (2012). Role of dopamine receptors in ADHD: a systematic meta-analysis. Molecular Neurobiology, 45(3), 605-620. doi:10.1007/s12035-012-8278-5 
84. Xu, H., Kellendonk, C. B., Simpson, E. H., Keilp, J. G., Bruder, G. E., Polan, H. J., . . . Gilliam, T. C. (2007). DRD2 C957T polymorphism interacts with the COMT Val158Met polymorphism in human working memory ability. Schizophrenia Research, 90(1-3), 104-107.

85. Zai, G., Robbins, T. W., Sahakian, B. J., \& Kennedy, J. L. (2017). A review of molecular genetic studies of neurocognitive deficits in schizophrenia. Neuroscience and Biobehavioral Reviews, 72(Supplement C), 50-67. doi:10.1016/j.neubiorev.2016.10.024

86. Zhang, Y., Bertolino, A., Fazio, L., Blasi, G., Rampino, A., Romano, R., . . Sadee, W. (2007). Polymorphisms in human dopamine D2 receptor gene affect gene expression, splicing, and neuronal activity during working memory. Proceedings of the National Academy of Sciences of the United States of America, 104(51), 20552-20557. doi:10.1073/pnas.0707106104 
Figure 1. Flow diagram of literature search and study inclusion. Note that the number of studies included in the meta-analysis does not match with the total number of executive function (EF) measures, as some studies measured more than one EF domain or reported findings for both Taq1A and C957T polymorphisms. 
Figure 2. Forest plot for random effects between-group meta-analysis comparing the ANKK1 Taq1A schizophrenia risk allele A1 carriers (A1+) to the non-carriers (A1-) in their working memory (WM) performance. Both overall effects and results from the subgroup analyses investigating phonological WM and visual/visuospatial WM tasks are presented. 
Figure 3. Forest plot for random effects between-group meta-analysis comparing the ANKK1 Taq1A schizophrenia risk allele A1 carriers (A1+) to the non-carriers (A1-) in their cognitive flexibility task performance. 
Figure 4. Forest plots for random effects between-group meta-analyses comparing the following DRD2 C957T genotype groups in their working memory (WM) performance: a) CC vs TT, b) CC vs CT, c) CT vs TT. Both overall effects and results from the subgroup analyses investigating phonological WM and visual/visuospatial WM tasks are presented. 
Figure 5. Forest plots for random effects between-group meta-analyses comparing the following DRD2 C957T genotype groups in their cognitive flexibility test performance: a) CC vs TT, b) CC vs CT, c) CT vs TT. 
Figure 6. Forest plots for random effects between-group meta-analyses comparing the following DRD2 C957T genotype groups in their response inhibition task performance: a) CC vs TT, b) CC vs CT, c) CT vs TT. 